\title{
Modernidad y anarquía: sobre lo colectivo en las crónicas de Rafael Barrett
}

\author{
MODERNITY AND ANARCHY: ON THE COLLECTIVE IN THE CHRONICLES OF \\ RAFAEL BARRETT
}

MODERNIDADE E ANARQUIA: SOBRE O COLETIVO NAS CRÔNICAS DE RAFAEL BARRETT

Leandro Delgado *1

ledelgad@ucu.edu.uy

\section{Resumen}

Junto con su noción de progreso, el proyecto de la modernidad es criticado habitualmente por el pensamiento ambiental. Sin embargo, en diferentes momentos del siglo XX, surgen algunas concepciones que ven, en este proyecto, la posibilidad de lograr la plena integración entre naturaleza y humanidad. Este artículo presenta las reflexiones del cronista anarquista y modernista español-paraguayo Rafael Barrett (1876-1910) con el objetivo de señalar elementos de un pensamiento ambiental presentes en su proyecto moderno. El artículo destaca conceptos clave de modernidad en las crónicas de Barrett y, a partir de entonces, propone un diálogo con la noción de "lo colectivo" de Bruno Latour donde se revelan dos lecturas de la obra de Barrett que pueden ser consideradas contradictorias: al tiempo que considera un mundo compartido por seres humanos y no humanos, ubica al ser humano en una posición jerárquica que lo habilita a tomar decisiones sobre el resto de los seres vivos. Finalmente, propone una noción anarquista de individuación que trasciende la contradicción y que afirma este lugar jerárquico para alcanzar, justamente, la integración con la naturaleza.

Palabras clave: modernidad, anarquismo, Rafael Barrett, humanidades ambientales, literatura hispanoamericana

\begin{abstract}
Along with its notion of progress, the project of modernity is regularly criticized by environmental thinkers. However, at different times in the 20th century, some conceptions emerged that see in this project the possibility of ultimately achieving full integration between nature and humanity. This article presents the reflections of the Spanish-Paraguayan anarchist and modernist chronicler Rafael Barrett (1876-1910)

$1 *$ Universidad católica del Uruguay

Tekoporá ${ }^{\circledR}$. Centro Universitario de la Región Este. Universidad de la República (C) Delgado. (2021)

Este es un artículo de Acceso Abierto distribuido bajo licencia Creative Commons (CC BY NC 4.0)
\end{abstract}


with the aim of presenting the elements of an environmental thought as part of the modern project. The article begins with key concepts of modernity present in Barrett's chronicles. From there, I propose a dialogue with Bruno Latour's notion of "the collective" and two possible readings of Barrett's work that turn out to be contradictory: while he considers a common and shared world between human and non-human beings, he locates human beings in a hierarchical position that enables them to make decisions about other living beings. Finally, he proposes the anarchist notion of individuation as one that transcends this contradiction and affirms this hierarchical place in order to achieve integration with nature.

Keywords: modernity, anarchism, Rafael Barrett, environmental humanities, Spanish American literature

\section{Resumo}

Junto com sua noção de progresso, o projeto de modernidade é regularmente criticado pelo pensamento ambiental. No entanto, em diferentes momentos do século $X X$, surgiram algumas concepções que veem neste projeto a possibilidade, em última instância, de alcançar a integração plena entre natureza e humanidade. Este artigo apresenta as reflexões do cronista anarquista e modernista hispano-paraguaio Rafael Barrett (1876-1910) com o objetivo de apresentar os elementos de um pensamento ambientalista presentes em seu projeto de modernidade. O artigo destaca os conceitos-chave da modernidade nas crônicas de Barrett. A partir daí, propõe um diálogo com a noção de "coletivo" de Bruno Latour e duas leituras possíveis da obra de Barrett que se revelam contraditórias: ao considerar um mundo comum $e$ compartilhado entre seres humanos e não humanos, ele localiza o ser humano em uma posição hierárquica que lhe permite tomar decisões sobre os demais seres vivos. Por fim, propõe a noção anarquista de individuação como aquela que transcende a contradição e que nos permite afirmar esse lugar hierárquico para se conseguir a integração com a natureza.

Palavras-chave: modernidade, anarquismo, Rafael Barrett, ecologia política, literatura hispano-americana 


\section{Introducción}

Abordar el complejo mapa de la modernidad, entendida como la transformación vertiginosa de la experiencia del mundo social, cultural y político, ha sido una tarea vastísima que atraviesa todo el pensamiento occidental, así como revivida y discutida en las últimas décadas con el surgimiento del pensamiento ambiental. Sin ánimo de ser exhaustivo, una revisión breve y puntual de algunos de sus elementos principales servirá de encuadre para ubicar el pensamiento de Rafael Barrett en el atribulado fin de siècle del sur del continente latinoamericano, así como para comprender su lugar excéntrico y novedoso dentro del proyecto moderno. $^{2}$

Entendida como "proyecto", la modernidad se remonta, en primera instancia, a los filósofos de la Ilustración y sus intentos para desarrollar una "ciencia objetiva", una ley universal y moral y, finalmente, un arte autónomo que responda a su propia lógica e intereses. En definitiva, la inspiración inicial de esta voluntad estuvo orientada a alcanzar la felicidad de todos los seres humanos a través de la justicia de las instituciones, del progreso moral y, principalmente para este análisis, del control de las fuerzas naturales (Habermas, s/f, p.9). Este dominio de la naturaleza aseguraría la liberación del hombre respecto de todo aquello que lo mantenía sometido a fuerzas que escapaban a su voluntad, tales como el pensamiento irracional, los mitos, la religión, la pobreza y las mismas catástrofes naturales (Harvey, 2004, p.26).

En términos estrictos, el término "moderno" refiere a la conciencia de una época que se identifica a partir de su diferencia con el pasado de la "antigüedad", por lo cual se considera a sí misma como el resultado de una transición de lo viejo hacia lo nuevo (Habermas, s/f, p.3) y que determina, por lo tanto, una relación distinta hasta el momento con esa antigüedad que no incluye, en primera instancia, ningún rechazo. Con la Ilustración francesa, la mirada hacia la antigüedad habría cambiado drásticamente a partir de la creencia en el progreso infinito y en el ideal de alcanzar la perfección de un sistema social y moral que descansaba sobre la confianza en la ciencia (p.4). La ruptura de este vínculo con la antigüedad permite comprender mejor la concepción de un tiempo lineal o histórico en la modernidad que se ve empujado forzosamente hacia adelante en la consecución del perfeccionamiento.

La ruptura con el conocimiento del pasado y con la tradición cultural se volvió central en la reflexión de los filósofos y extensiva a las acciones sucesivas de estados y naciones. Así, detrás de la destrucción y posterior reconstrucción de París en mitad del siglo XIX (por el Baron de Haussman) o de los grandes proyectos urbanísticos de Nueva York a mitad del siglo XX (por Robert Moses) reside uno de

\footnotetext{
${ }^{2}$ Este abordaje inicial no incluye una caracterización del modernismo como experiencia estética ni como movimiento artístico y/o literario. Su mención se va a limitar, a lo largo del artículo, a menciones oportunas y esporádicas con el fin de contribuir a una mejor comprensión, también, de la modernidad de Barrett en su percepción de la naturaleza.
} 
los elementos fundamentales de la modernidad, conocido como "destrucción creadora" (Harvey, 1998, p.31). ${ }^{3}$ De esta forma, la modernidad se fue convirtiendo en una experiencia que reunía los valores eternos e inmutables que resultan de la emancipación humana junto con aquellos que promueven la destrucción constante como forma de asegurar esta emancipación.

Estas nociones pueden ayudar a comprender cómo la modernidad presenta una tensión inevitable entre lo eterno y lo efímero, entre la construcción y la destrucción (pp.30-33). Para el objetivo de este artículo, la noción de destrucción creadora será exacerbada por el pensamiento de Friedrich Nietzsche y de Mikhail Bakunin, ${ }^{4}$ quienes tuvieron especial incidencia en el pensamiento anarquista rioplatense de fines del siglo XIX y comienzos del XX, y en la obra de Barrett en particular (Delgado, 2013). Esta noción de una destrucción creadora como base del impulso moderno es constante en la obra de Barrett.

Estamos solos porque somos más fuertes. Hemos aceptado la plena responsabilidad de nuestro destino. Hemos rasgado el cielorraso mitológico que nos separaba del firmamento vacío, y por fin miramos el universo cara a cara. Hemos rechazado la ayuda de los Dioses. Muchos les debíamos, pero les hemos despedido bien pagados. Por nuestra cuenta pelearemos. La guerra es ahora únicamente nuestra, y nuestro el amor, que es otra forma de la guerra. No nos alquilarán un paraíso: intentaremos fabricarlo con nuestras propias manos. Solo nosotros fecundaremos a nuestras vírgenes; nosotros solos nos redimiremos. Abrazados a la tierra, la desgarraremos para que críe; enterraremos en ella la simiente de nuestros cuerpos. Agujerearemos sus montañas, tenderemos puentes por encima de sus más hondos tajos, uniremos los hemisferios y mezclaremos los mares. Y si el horror de un cataclismo nos detiene un instante, no por eso nos abandonará la noble esperanza. No sufriremos de nuestros pecados y como maldición de nuestro origen, sino como episodio natural del eterno combate. Detrás de la tierra rebelde no estará ya la terquedad invulnerable y estúpida de un tirano todopoderoso, sino el desorden pasajero de fuerzas destinadas a espiritualizarse tarde o temprano bajo nuestra acción y nuestro genio. (Barrett, 1912b, pp.124-125)

Esta tensión o contradicción constitutiva de la modernidad, entre lo eterno y lo efímero, entre la construcción y la destrucción remite, de manera ineludible, a un rechazo y/o atracción frente a la experiencia moderna. En efecto, se trata de una

\footnotetext{
${ }^{3}$ El concepto de "destrucción creadora" es uno de los elementos centrales del pensamiento anarquista, como se verá más adelante. Para ahondar en la relación entre el pensamiento anarquista y la modernidad rioplatense, se pueden consultar los trabajos de Pablo Ansolabehere (2011), Delgado (2010; 2012; 2015; 2017) y Marcos Wasem (2015).

${ }^{4}$ No entraré aquí en las diferencias y coincidencias entre el pensamiento nietzscheano y el anarquismo. A efectos de este trabajo, se los considera parte de un mismo concepto de liberación radical de todos los individuos. Para ahondar en las relaciones entre Nietzsche y el pensamiento anarquista se puede consultar John Moore (1997; 2004), Andrew M. Koch (2004) y John Carroll (2003).
} 
experiencia doble y contradictoria señalada de manera muy particular para el fin del siglo XIX. Así, Marshall Berman (1988) distingue dos actitudes o dos experiencias que son opuestas y simultáneas frente a la modernidad. Por un lado, observa en los pensadores del siglo XIX una contradicción presente en el interior de un solo individuo al punto de convertirse, este mismo individuo, en defensor y enemigo de la modernidad de acuerdo con una tensión que se manifestó, en la literatura del período, a través de ironías y paradojas que potenciaron las formas de expresar la contradicción. Por otro, los modernos del siglo XX habrían polarizado esta tensión luego de las masacres de dos guerras mundiales, en una suerte de escisión de orden mayor. Mientras unos defendieron acríticamente el proyecto moderno, ${ }^{5}$ otros lo condenaron de manera pesimista y terminal sin ningún punto de contacto entre ambas actitudes ${ }^{6}$ (p.24). En este sentido, no es difícil ubicar a Barrett en la primera modernidad, tal como puede inferirse, también, del pasaje citado.

Más recientemente, Bruno Latour (2007) señala una contradicción de mayor complejidad o, de otra forma, una sucesión o superposición de dualidades contradictorias al punto de concluir, finalmente, que la modernidad nunca ocurrió. En efecto, ser "moderno" significa, para Latour, la existencia simultánea de dos tipos de prácticas que deben permanecer distintas "aunque hace poco tiempo han dejado de serlo" (p.28). Así, el primer grupo de prácticas (a las que agrupa bajo el término "traducción") crea mezclas entre géneros, es decir, "híbridos" entre naturaleza y cultura, siendo los "híbridos" producciones o entidades que resultan de la fusión entre elementos naturales y sociales. El segundo grupo de prácticas (a las que denomina de "purificación") genera dos zonas ontológicas que identifica como el mundo humano y el mundo no humano, mundos que no habrían estado separados en una fase pre moderna pero que se habrían distanciado progresivamente. La contradicción se presenta en que, a medida en que aumenta la proliferación de híbridos, la distancia entre el mundo natural y social es cada vez mayor al haber afirmado la separación entre naturaleza y cultura (pp.27-28).

En años recientes, Latour fue abandonando su reflexión sobre los híbridos y profundizando la discusión sobre las estrategias políticas que subyacen en la separación entre naturaleza y cultura, entre el mundo humano y no humano, y entre sujetos y objetos en una reflexión que tiende a elaborar, o al menos reflexionar, sobre la noción de una democracia donde participe todo lo animado e inanimado. Su particular ecología política lo ha llevado a plantear una nueva ontología con particular atención en la presencia de los objetos (Latour, 2004; 2017 ; 2018).

Son numerosas las críticas del pensamiento ambiental al proyecto moderno así como sus vínculos con la antigüedad. Las críticas se remontan a la filosofía plátonica y, más recientemente, a la separación cartesiana entre mente y materia,

\footnotetext{
${ }^{5}$ Aquí se puede mencionar la pléyade de autores estadounidenses de la posguerra que afirmaron el paradigma funcionalista, tales como Robert Merton, Paul Lazarsfeld y todos los investigadores reunidos alrededor de la llamada Investigación Administrada.

${ }^{6}$ Entre estos autores se destacan los integrantes de la Escuela de Frankfurt, en particular el pensamiento de Theodore Adorno y Herbert Marcuse.
} 
división ontológica que habría fomentado la distancia cada vez mayor entre naturaleza y cultura, así como entre el mundo humano y no humano. Últimamente, la crítica a la idea de progreso apunta a los perjuicios ambientales como consecuencia de la extracción ilimitada de recursos naturales finitos. Además de los varios trabajos de Latour, se puede mencionar, de modo muy sucinto, los aportes desde la historia ambiental (William Cronon, 1994; 1995; Donald Worster, 1995; 1996) desde la filosofía (Agamben, 1998; 2004), desde la teoría feminista (Donna Haraway, 1991; 2003; 2016) o desde los estudios literarios (Timothy Morton, 2016; 2017) entre los más destacados.

En este análisis, se presta atención a ciertas zonas de la producción de Barrett vinculadas con el mundo de la selva, de modo de detectar los vínculos particulares entre el mundo humano y no humano. A partir de entonces, el artículo hace dialogar esta producción con la concepción de "lo colectivo" de Bruno Latour (2004) de forma de presentar los elementos de un pensamiento ambiental de parte de Barrett quien, de manera aparentemente contradictoria, afirma la existencia de una jerarquía al interior de un mundo que considera compartido por seres humanos y no humanos. El pensamiento anarquista, finalmente, haría posible la simultaneidad de estas dos actitudes, como se verá sobre el final.

Con este objetivo, este trabajo se concentra en el análisis de cinco crónicas repartidas en varios de sus volúmenes: "El paisaje" (1912a, pp.169-173), "El mercado" (1911, p.7), "En la estancia” (1911, pp.13-17), "Vivisecciones" (1912b, pp.61-64) y "El retorno a la tierra" (s/f, pp.85-87) sin perjuicio de hacer consideraciones generales sobre el volumen El dolor paraguayo (1911) así como menciones puntuales en la totalidad de su obra, cuyos casos se referencian oportunamente.

\section{La experiencia moderna de la selva}

Sobre el modernismo literario hispanoamericano, Susana Rotker (1992) señala la tendencia de los cronistas modernistas-en particular José Martí-a considerar a la naturaleza como el marco de referencia de la crónica (1992, p.145). En la primera década del siglo, Barrett ${ }^{7}$ ya observaba en sus contemporáneos esta apelación a la naturaleza como mera referencia y así la hace extensiva a la cultura occidental, que apenas se nutre culturalmente de las particularidades y novedades "naturales" del continente conquistado:

Los épicos descubridores del siglo XVI apenas hablan de los grandiosos paisajes americanos. Quizá estuvieron demasiado entretenidos para retrasarse a tales menudencias. Lo cierto es que los buques cargados de tesoros no trajeron al Viejo Mundo una sola

\footnotetext{
${ }^{7}$ Las circunstancias novelescas por las que Rafael Barrett se convirtió en una figura mítica y fundacional en la historia literaria paraguaya trascienden los límites de este artículo. Para un abordaje y profundización en la vida de Rafael Barrett, se puede consultar a Vladimiro Muñoz (1977), Gregorio Morán (2007) y Virginia Martínez (2017) y para los trabajos críticos sobre su obra a Luis Hierro Gambardella (1967), Augusto Roa Bastos (1978), Francisco Corral (1994), Martín Albornoz (2006-7; 2007) y Delgado (2012).
} 
emoción artística, y que cualquier gran inocente de Gautier o de Maupassant por los domésticos rincones de Europa es más interesante para una inteligencia refinada. Hasta Rousseau, Humboldt y Chateaubriand, la naturaleza no preocupa por sí misma. Es el fondo de las narraciones legendarias o de las intrigas novelescas, un fondo hecho siempre de las mismas cuatro pinceladas convencionales, una decoración que sirve para todas las comedias. El tema único es el hombre, porque las divinidades son hombres también. La naturaleza es un acompañamiento insignificante. (Barrett, 1912a, p.170-171)

Sin embargo, Barrett va más allá de esta consideración y emprende la tarea de adentrarse en la selva paraguaya para describir impresiones, sensaciones y reflexiones sobre la naturaleza menos como una referencia decorativa y exótica y más desde la transcripción fiel de una experiencia cercana e íntima que logra reunir al cronista, al anarquista y al hombre de ciencias (Delgado, 2012; 2017). Esta tarea no es menor ni la alienta un simple espíritu de aventura: en el interior frondoso, fascinante y sombrío de la selva ocurre la esclavitud de los trabajadores yerbateros fuera de las luces bienvenidas del progreso urbano. De esta forma, Barrett establece y denuncia, en varias de sus crónicas y panfletos, principalmente El Dolor Paraguayo y Lo que son los yerbales, la relación directa entre el origen de los recursos a ser consumidos en la ciudad y la explotación salvaje de los trabajadores en los recintos ocultos tras la vegetación (Delgado, 2017; Roa Bastos, 1978).

Todo el volumen de El dolor paraguayo (la única recopilación de crónicas reunidas y editadas en vida por Barrett) es un proceso gradual de apertura del campo perceptivo en su experiencia de la selva (Delgado, 2017). Este proceso se inicia con anotaciones impresionistas, a la manera de un viajero, para culminar en una denuncia política vehemente habilitada por unos conocimientos científicos y una capacidad de escritura que trascienden la retórica anarquista, habitualmente grandilocuente. A las variadas, disímiles impresiones de la naturaleza paraguaya se agregan, gradualmente, reflexiones específicas sobre la explotación de los obreros yerbateros e incluyen, hacia el final del volumen, textos escritos para ser leídos en conferencias a los trabajadores. Su apertura del campo perceptivo, que incluye lo visual, lo sonoro y lo táctil, lleva al cronista a reflexionar sobre las relaciones entre los mundos humano y no humano que resultan en una indefinición de los límites entre naturaleza y cultura.

El breve fragmento titulado "El mercado" que abre El dolor paraguayo, ya presenta elementos visuales y narrativos característicos del modernismo literario y deja, por el momento, toda reivindicación social y económica de lado. Sin embargo, la crítica se insinúa en los diversos elementos impresionistas y simbolistas dispuestos casi pictóricamente:

Bajo un sol que a la pradera muy verde volatiliza matices y penumbras, las mujeres, envueltas en sábanas aleteadoras al viento, parecen una bandada de pájaros blancos que no acaba de posarse. Pero sus cuerpos, erguidos o acurrucados, están inmóviles. Con un noble ademán profético guardan de la luz sus negros ojos, señores de la 
llanura. Al lado de sus pies morenos, que al correr acarician la tierra, hay cosas humildes y necesarias, huevos tibios, "chipa" tierno que sirve de pan y de postre, leche, mandioca, maíz, naranjas doradas y sandías frescas como una fuente a la sombra. Apenas se habla. Nadie ofrece, regatea ni discute. Una dignidad melancólica en las figuras y en los movimientos. Las niñas tienen miradas serias y el reflejo de un pasado sobre su frente vacía. Más tarde abandonarán al emponchado su cintura cimbreante de hembras descalzas, sus senos obscuros y su boca parda, con el mismo gesto silencioso. (Barrett, 1911, p.7)

El modernismo del pasaje se aprecia, principalmente, en la conmoción visual del instante, descrita aquí como un contraste de formas, luces y colores. Este instante visual está determinado por una "volatilización" de las imágenes que desdibuja las líneas, así como las pinceladas breves de los impresionistas reconstruían visualmente la presencia vibrante, inquieta y "natural" de lo observado. Las sábanas blancas como pájaros contrastan con la oscuridad de ciertas zonas del paisaje y, en particular, con la inmovilidad de los cuerpos. Este contraste entre luces y sombras, así como entre movimiento y quietud, determinan una tensión tanto cromática como cinética que provocan el éxtasis visual (Delgado, 2017).

Progresivamente, las imágenes adquieren su espesor y trascendencia simbolistas. La insinuación indigenista se revela en algunos detalles como los pies descalzos, los ojos negros, los senos oscuros o la boca parda de las mujeres que Barrett vincula con un pasado, mítico o histórico, que brilla en sus ojos. El indigenismo modernista consiste en esta "transposición sentimental" a la realidad de una imagen idealizada del pasado (Gullol, 1974, p. 271). Este indigenismo de las primeras impresiones, sin embargo, no tiene un afán evasivo y se aleja del indianismo decorativo del siglo XIX. El indigenismo de la visión de Barrett anuncia una presencia y visión críticas. ${ }^{8}$

Los elementos del paisaje sugieren un pretérito acontecimiento misterioso que se hace manifiesto en el presente de la contemplación: el silencio, las sombras y la penumbra insinúan un malestar a punto de revelarse en las proximidades de la intensa luz solar. La presencia significativa del pasado es explícita por Barrett en la interpretación de la mirada de las niñas, "reflejo de un pasado sobre su frente vacía" (Barrett, 1911, p.7). Muy particularmente, la metaforización de los ojos negros determina un contraste marcado entre la omnipresencia femenina en el paisaje y la masculinización puntual de los ojos, "señores de la llanura" (p.7).

De esta forma, el pasado misterioso adquiere todo su peso histórico, porque pone en evidencia la ausencia de hombres en la contemplación. La omnipresencia femenina parece evocar el exterminio de los hombres durante la guerra del Paraguay, tragedia que Barrett denuncia permanentemente en El dolor paraguayo. De esta forma, los ojos de las mujeres se presentan como sustituyendo a los hombres que faltan. Así como la presencia indigenista era un primer indicio de la mirada crítica del observador, también la omnipresencia femenina está orientada

\footnotetext{
${ }^{8}$ Sobre las diferencias entre el indianismo del siglo XIX y el indigenismo del siglo XX, se puede consultar José Alcina Franch (1990).
} 
en esta dirección.

La descripción del paisaje se construye sobre otros sentidos que amplían la percepción. Los "huevos tibios" y el "chipa tierno" ofrecen sensaciones táctiles que permiten captar una relación cercana a los objetos. Las sensaciones táctiles y térmicas son escasas en la literatura modernista (Bollo, 1976, pp.68-69) y esta dimensión sensorial de la crónica permite apreciar la originalidad del modernismo de Barrett. El detalle de la temperatura y la textura de las cosas permite al lector acceder a la experiencia sensual del paisaje, en particular al contacto directo de los pies de las mujeres "que al correr acarician la tierra". A través de estos detalles que recuperan el sentido del tacto, es posible advertir la transformación de la contemplación distante en una experiencia más cercana y comprometida.

Así, en los detalles de la descripción, se puede observar cómo el autor presenta una suerte de "inscripción" de datos históricos en el mundo material. Se trata, no obstante, de una experiencia fenomenológica, en el sentido de que la valoración o un determinado juicio surge a partir de una contemplación que parece muchas veces errática (Merleau Ponty, 1993, pp. 63-65). Este vínculo entre el mundo material de la contemplación y el surgimiento gradual de su espesor histórico y cultural van anunciando tanto la adjudicación de una historia propia y particular de la selva como la detección del "estatus" cultural de ciertas entidades consideradas como "naturales".

La melancolía, la frente vacía, los gestos silenciosos de las mujeres insinúan una incomodidad que se va acentuando en las crónicas siguientes en una insistencia que parece remitir a un cuestionamiento de la relación tradicional entre el mundo humano y no humano, pues se trata siempre de una relación marcada por la distancia o la extrañeza. ${ }^{9}$ El vínculo se presenta conflictivo en múltiples registros del análisis, al punto de lograr expresar la imposibilidad de encontrar en la naturaleza, la selva en este caso, cualquier interpretación, es decir, de expresar la negación de cualquier sentido sobre su mera existencia. Esta negación se realiza, paradójicamente, a través de un repertorio amplio de recursos expresivos, como se verá a continuación.

A medida que la lectura avanza, Barrett logrará presentar a la selva a partir de sí misma, es decir, dando elementos para la elaboración de una noción de naturaleza no subsidiaria de modelos económicos o de desarrollo particulares. ${ }^{10} \mathrm{De}$ esta forma, parece no encontrar otra alternativa que afirmarla como el límite o la negación de toda interpretación. En la crónica "En la estancia", describe la experiencia de la selva como una de soledad extrema, donde el cronista no está acompañado, ni siquiera, de su propia interpretación, es decir, del sentido del mundo que está habitando.

\footnotetext{
${ }^{9}$ Para un desarrollo pormenorizado de la experiencia perceptiva de Barrett sobre la selva paraguaya a través de sus crónicas se puede consultar a Delgado (2017).

${ }^{10}$ Las diferentes concepciones de naturaleza a lo largo de la historia latinoamericana han sido históricamente subsidiarias de modelos económicos o de desarrollo, tal como es analizado por Eduardo Gudynas (1999).
} 
Ni el azar mismo nos concilia con esta soledad definitiva. Nada de humano nos circunda. Pudo el antropoide, tronco de nuestra extraña especie, no haber salido jamás del misterioso no ser a donde tantas otras especies tornaron al cumplirse los tiempos, y estos llanos alternarían idénticamente su ritmo infinito, y estos montes exhalarían en la lóbrega intimidad de su fondo, igual aliento salvaje. La inmensidad nos tiene prisioneros. "No", dice el cielo, ensanchado por la tierra; "no", dice el árbol que levanta sobre la siniestra espesura sus brazos eternos; "no", repiten los buitres inmóviles, espías de la muerte. (Barrett, 1911, pp.13-14, mi énfasis)

A partir de este pasaje voy a proponer dos posibles lecturas respecto del silencio de la selva en su relación con la noción de "lo colectivo" de Bruno Latour que pueden echar luz sobre la conflictiva relación entre naturaleza y cultura y que Barrett presenta de manera sostenida. En este trabajo, ambas lecturas pueden resultar contradictorias entre sí. No obstante, la afirmación de esta contradicción puede habilitar a generar una noción más completa sobre la oposición Naturaleza/Cultura propuesta por Latour (2017), es decir, una que tenga en cuenta sus propias contradicciones como un rasgo o elemento de incertidumbre necesario para seguir reflexionando sobre la oposición.

La apelación a Latour obedece al lugar novedoso y crítico que ocupa en el pensamiento ambiental (Karlsson, 2015, p.350). En su crítica ontológica, Latour interpela a la ecología política por no cuestionar el binomio conceptual "política" y "naturaleza" (Latour, 2004, p. 2) al punto de afirmar que la ecología política debe abandonar la "naturaleza" como categoría de análisis. Asimismo, el objetivo de la ecología política no debe confundirse con la acción política de los activismos ambientalistas (p. 20) sino sobre la reflexión ontológica sobre naturaleza y cultura como partes de un mismo concepto al que define como "lo colectivo". Esta concepción tiene varios puntos en común con las reflexiones de Barrett, como se verá a continuación.

\section{El silencio como negación de lo colectivo}

Latour parte del cuestionamiento tanto de la expresión "relación con el mundo" como del término "naturaleza". En el primer caso, esta relación supone la existencia de dos dominios, naturaleza y cultura, los cuales, distintos pero inseparables, condicionan mutuamente sus propias definiciones. De esta forma, explica, no existen dos dominios como tales sino como dos partes de un solo concepto, para lo cual propone emplear la expresión "Naturaleza/Cultura" (Latour, 2017, pp. 29-30). A partir de entonces, la expresión "pertenecer a la naturaleza" no tiene sentido, ya que la naturaleza no existe sino como la mitad de este par definido por un concepto único (p.33). No se trata entonces de buscar la pertenencia a uno u otro dominio sino de hacer foco en la oposición mencionada para ubicar toda 
manifestación viviente en el ámbito de lo colectivo. ${ }^{11}$

En su ecología política, Latour (2004) remite a las cosmovisiones de las comunidades originarias amazónicas donde la naturaleza es inexistente como categoría y donde los humanos y no humanos intercambian posiciones y perspectivas conformando un "pluriverso" donde ningún grupo está más cerca o más lejos de la naturaleza. ${ }^{12}$ De esta forma, el conocimiento de la naturaleza no proviene de una "parálisis" del movimiento de un mundo común a humanos y no humanos para una observación determinada y puntual sino de "recolectar" la multiplicidad de asociaciones entre humanos y no humanos sin recurrir a la segregación de acuerdo con cualidades "primarias" o "secundarias" (p. 55).

En la noción de colectivo propuesta, Latour se pregunta quién estaría habilitado para hablar públicamente, ya que una posible condición de ciudadanía sólo podría ser relevante (para la vida pública) en la medida en que se defina lo colectivo como una asamblea de seres capaces de hablar. Pero ¿cómo hacer participar al conjunto de los seres no humanos cuando no hablan o cuando existe el acuerdo de que los científicos serían los únicos portavoces, los únicos habilitados para hablar en nombre de todos los seres no humanos o para hablar de los "hechos tal cual son"? ¿Quiénes serían entonces sus "portavoces”? Latour propone superar estas dificultades en la medida en que el humano pueda hablar sobre los no humanos "con su participación" (p. 68, énfasis de Latour). Estas preguntas parecen sugeridas en el citado pasaje de Barrett.

En efecto, en su crónica, la repetición de una negación ("no") sería la expresión de uno de los tantos "mitos" de la modernidad, aquella que opone, de manera aberrante, una naturaleza "muda" a unos hechos que hablan ("speaking facts"), hechos que sólo pueden ser interpretados por los científicos $\mathrm{y}$, en consecuencia, haciendo de su habla una propiedad indisputable a la que considera una suerte de "ventriloquismo" (Latour, 2004, p. 68). La negación estaría remitiendo a una manifestación de los "hechos naturales" que sólo podrían ser interpretados por los científicos. La oposición entre naturaleza muda y los hechos que "hablan por sí mismos" se presenta, para Latour, como una vía para discutir quién estaría habilitado, además de los científicos, a hablar en nombre de los seres no humanos en un ámbito donde se establecen asociaciones entre todos los seres vivos que definen "lo colectivo".

Sin embargo, el Barrett científico parece desestimar un colectivo conformado por estas asociaciones. Antes bien, el ser humano se ubicaría en la cúspide de este mundo común a todos los seres desde que tiene, ante todo, una agencia que le permite presentarse e imponerse como tal ante sí mismo y ante el resto de los seres. En su crítica a las sociedades protectoras de animales de comienzos de siglo frente a las vivisecciones de perros para la investigación en universidades, Barrett no duda en abogar por la defensa del interés científico ni en

\footnotetext{
${ }^{11}$ En este aspecto, Latour es crítico respecto de los movimientos ecologistas porque no han logrado librarse de una noción de naturaleza que está entendida como una dimensión autónoma que no tiene en cuenta la cualidad inseparable de la oposición que integra (2004, pp. 25-27).

12 Más adelante se presentarán estas cosmovisiones.
} 
negarles, en consecuencia, toda posibilidad de agencia a los no humanos:

El que hace sufrir a un perro, sin causa legítima, es un malvado. Pero lo esencial es corregir, sanar, proteger, al malvado. Proteger al perro es secundario. Mientras los perros no se protejan a sí mismos, seguirán siendo perros.

¿Proteger a los perros y desarmar la ciencia? ¿Por qué? [. . .] Refiriéndonos a lo más urgente, a la tuberculosis, al cáncer, se prohibiría la vivisección? Se prohibiría experimentar sobre un conejo vivo a un Jenner, que ensayó en su hijo la vacuna [. . .]? El ideal de no herir materialmente a nadie es imposible y falso. No nos estremecemos, no respiramos sin asesinar en torno. Un pensamiento generoso no se yergue sin hacer víctimas invisibles. Desterremos el egoísmo, y matemos entonces en paz. Matemos con amor. (Barrett, 1912b, p. 65)

La crítica al pensamiento de Barrett desde la perspectiva latouriana resulta, hasta aquí, clara y consistente. En definitiva, la negación repetida de parte de todos los seres vivos ante la contemplación en tanto elementos mudos de la naturaleza parece consonante con la negación de toda agencia a los perros viviseccionados, ya que no tendrían la capacidad de protegerse a sí mismos o, de otra forma, no serían capaces de participar en la vida pública del colectivo (a través del habla). Este punto es crítico, porque Barrett insiste más en negar la participación en un mundo común que en la existencia de este mundo. En otras palabras, se puede pensar en la posibilidad de que Barrett reconoce un mundo conformado por humanos y no humanos pero no formando asociaciones sino relaciones de dominación que deben ser, eventualmente, afirmadas.

A continuación, se puede trazar otra lectura a partir de la noción de la naturaleza muda de Barrett en el sentido contrario, es decir, de acuerdo con una interpretación conducente a comprender este mundo común como un colectivo al punto de compartir, unos y otros, no solo un cimiento material sino también todo lo que puede existir en este colectivo como manifestación compartida de una vida mental o espiritual.

\section{El silencio como fin de la interpretación}

En la selva descrita por Barrett, el tiempo no es percibido como una sucesión lineal de momentos, uno a continuación del otro, sino como un movimiento o una superposición de movimientos cíclicos. Así, resulta llamativa la mención a un retorno de todas las especies animales a un "misterioso no ser" "al cumplirse los tiempos" (Barrett, 1911, pp.13-14), es decir como después de un período en el que todas las especies habrían de coincidir necesariamente o, en otras palabras, como un estado anterior y posterior a la vez del que habría emergido, y habrá de emerger, la especie humana. El eterno retorno determina así un estado del "no ser" compartido por humanos y no humanos tanto en el origen como en el fin de los tiempos.

En su relectura del filósofo alemán Eric Voegelin, Latour (2017) discute la 
noción del "tiempo del fin" presente en las tradiciones judía y cristiana, un fin que resulta no solo posible sino esperable. Sin embargo, explica, no se trata del fin de los tiempos en el tiempo que pasa sino más bien de la interrupción final del tiempo que pasa. En otras palabras, no es un tiempo ubicado al final de un tiempo que avanza sino de la interrupción de todos los momentos (p. 222). Así, este no ser parece reunir, en su ubicación fuera del tiempo y del espacio definidos por el tiempo histórico, a todas las manifestaciones concebibles de lo humano y lo no humano en una sola entidad, una suerte de conformación ontológica que agruparía, a su vez, a todo lo animado e inanimado.

En tal negación ontológica, la noción de un "misterioso no ser" altera o trastoca no solo la oposición tradicional entre naturaleza y cultura sino la noción misma de naturaleza. De esta forma, cualquier interpretación de la naturaleza desde la ciudad, desde la civilización o desde la cultura, parecen imposibles de ser realizadas, una imposibilidad que Barrett expresa de manera elocuente con la repetición obstinada de la negación ("no"). Se trata de una descripción plena del asombro y la fascinación propias del horror gótico romántico ${ }^{13}$ y finisecular que tiñe todas sus crónicas.

La imposibilidad de ver en la selva un sistema de signos se manifiesta en una paradoja: que los árboles y los animales puedan expresar, aunque fuera metafóricamente, una negación, estaría ofreciendo al observador señales demasiado concretas para una interpretación o construcción discursivas de la naturaleza. La paradoja se presenta al repetir constantemente "no" como afirmación del mundo material observado. La naturaleza sí existe, a pesar de la imposibilidad de su interpretación. En definitiva, el pasaje parece poner de relieve la necesidad de dejar de lado una noción de naturaleza que es siempre elaborada con elementos discursivos que necesitan ser deconstruidos (Latour, 2004, p. 25-27). El pasaje afirmaría, de esta forma, la necesidad de dejar de lado cualquier definición de naturaleza.

A la luz de esta negación simbólica y, simultáneamente, de afirmación material, se puede comprender mejor la condición ontológica del "misterioso no ser". Desde su misma adjetivación, se ubicaría fuera del mundo simbólico, al punto de que no podría siquiera ser pensado. En este punto se puede, apenas, conjeturar sobre la intención política del cronista finisecular, al menos en los términos planteados en cuanto hombre de ciencia comprometido con el avance civilizatorio. Sería posible imaginar este misterioso no ser como una entidad que no puede ser pensada en los términos definidos por la civilización, es decir, que no sería ni individual ni colectiva, que no puede identificarse, tampoco, como sujeto ni como objeto, y que sólo existiría en un tiempo desprovisto de toda datación o periodización. En este contexto, y desde la perspectiva moderna, se trataría de un ser humano cuyo abandono del tiempo y espacio tradicionales le permitirían

\footnotetext{
${ }^{13}$ Octavio Paz destaca la particular lectura del romanticismo alemán e inglés por el modernismo hispanoamericano en su conocido ensayo Los hijos del limo (1990).
} 
integrarse definitivamente al mundo no humano. ${ }^{14}$

A la luz de la noción latouriana de "lo colectivo" se puede ver, entonces, la comprensión explícita de Barrett sobre un vínculo inseparable entre el mundo humano y no humano. Sin embargo, esta cualidad de un mundo compartido por todas las especies no resulta solo del pasaje analizado. Son innumerables los momentos en que Barrett adjudica propiedades no humanas a los humanos como en "De paso" (1911, pp. 19-30). Asimismo, fusiona cualidades humanas y no humanas en criaturas mitológicas en "El pombero" (1911, pp. 59-62); reflexiona sobre la inteligencia racional y solidaria de los no humanos en "Hormigas" (1912b, pp. 33-36); observa el particular contacto entre humanos y no humanos en "Perros" (1912b, pp. 45-48), "Perros polizontes" (1912b, pp. 269-282) y "El progreso" (2012, pp.108-136). Aún más, esta concepción no se limita a unificar a todas las especies animales sino que incluye al reino vegetal en "Herborizando" (1911, pp. 39-42) y "El odio a los árboles" (1911, pp. 99-102), y al mineral en "Amatistas" (1912a, pp. 139-142) y “La poesía de las piedras" (1911, pp. 35-38) lo que conduce inevitablemente a una indiscriminación de las dimensiones de naturaleza y cultura en "Las bestias oráculos" (1911, pp. 43-48) y "Sueños" (1911, pp. 49-52). Aún más, existen varios otros pasajes que parecen ubicar a Barrett muy lejos de cualquier distinción jerárquica entre especies. El mismo científico que defendía a ultranza las vivisecciones de perros para el beneficio de la ciencia no parece ser el mismo que reflexiona sobre el lugar del hombre al interior del colectivo que integra, tal como se aprecia en este pasaje de "El paisaje", donde resume la integración completa entre naturaleza y cultura, entre el mundo humano y no humano, y entre el mundo material y espiritual.

Todo significa que lazos estrechos, entre las tinieblas, nos atan a las cosas. Melancólicos, tiernos o excitantes, los sentimientos que en nosotros despierta el paisaje son la expresión de una verdad. La verdad es que somos hermanos de la tierra, de los árboles, de las aguas y de las estrellas, y que cada día somos y nos sentimos más hermanos. Las metáforas que nos identifican con la naturaleza nos deslumbran. "El alma, dice Turguéniev, es una selva obscura". "Un paisaje, dice Amiel, es un estado del alma".

${ }^{14}$ En su lectura de Alexandre Kojeve, Giorgio Agamben (2004) presenta una figura del hombre y la naturaleza que habrían de adquirir en un mundo post histórico a través de una labor paciente de trabajo y "negación", la que permitiría al Homos Sapiens alcanzar su completud:

La desaparición del Hombre al final de la Historia no es una catástrofe cósmica: el Mundo natural permanece de acuerdo con lo que ha sido durante toda la eternidad. Y tampoco es una catástrofe biológica: el Hombre permanece vivo como animal en armonía con la Naturaleza o el Ser dado. Lo que desaparece es el Hombre propiamente dicho-es decir, la Acción que niega lo dado, y el Error, o, en general, el Sujeto opuesto al Objeto. De hecho, el fin del Tiempo humano o la Historia, es decir, la aniquilación definitiva del Hombre propiamente dicho o del individuo libre e histórico, significa simplemente el cese de la Acción en el sentido más estricto del término. Prácticamente, esto significa: la desaparición de guerras y revoluciones sangrientas. [. . .] Pero todo lo demás puede conservarse indefinidamente; arte, amor, juego, etc., etc.; en resumen, todo lo que hace feliz al Hombre. (Kojeve citado en Agamben, 2004, p. 6, énfasis de Agamben, mi traducción) 
No, no son metáforas. Si la sustancia de nuestro cuerpo es la misma que sube por el tallo de las plantas, se desliza con la corriente de los ríos y luce en el parpadeo de los astros, ¿por qué los astros, el mar y los bosques no han de desear, esperar, soñar? Nuestro más noble ideal, es que el sueño del mundo sea nuestro propio sueño. (Barrett, 1912a, pp.172-173)

No es objetivo de este trabajo entrar en la intimidad de los recursos escriturales, en los tropos que refuerzan la representación de un universo integrado por el mundo material y simbólico. Sin embargo, es importante recordar que Barrett elige el género de la crónica como unidad discursiva, género que probablemente le haya permitido navegar distintos registros de la experiencia literaria sin establecer necesariamente conexiones "lógicas" sino antes bien, perceptivas, intuitivas o poéticas. Además de sus conocimientos científicos y humanísticos, la presencia del yo narrador característica de la crónica hispanoamericana permite abordar diversas representaciones de la naturaleza de acuerdo con una diversidad de perspectivas. ${ }^{15}$

Como se dijo, la intención de este trabajo es comprender, de parte de Barrett, una convivencia entre dos concepciones aparentemente contradictorias: la existencia de una jerarquía al interior de un mundo común a seres humanos y no humanos, así como la de un mundo donde existe una integración completa entre naturaleza y cultura. Esta aparente contradicción puede ser considerada como el resultado de su inmersión en concepciones anarquistas y nietzscheanas que tienen sus correspondencias en el reciente pensamiento ambiental, tal como se analiza.

\section{De la contradicción a la individuación}

El concepto de "anarquía"16 permite ahondar en la concepción-presentada más arriba-sobre el problemático y "misterioso no ser". Si esta noción habilitó a pensar en las relaciones entre humanos y no humanos en los términos planteados por Latour, también lo hace en la problematización del concepto de "origen" tal como lo presentan los estudios ambientales. Estrictamente, la anarquía se define como el rechazo a todo principio, a toda causa inicial y a toda dependencia de cualquier ser respecto de un origen único (Colson, 2003, p.30). La anarquía es, a un mismo tiempo, el origen, el medio y el objetivo que permite afirmar la "diversidad ilimitada de los seres para componer un mundo sin jerarquías, sin dominación, sin otras dependencias que la libre asociación de fuerzas radicalmente libres y autónomas" (p.30).

\footnotetext{
${ }^{15}$ Este salto entre diferentes enfoques descriptivos participa de la indefinición característica de la crónica modernista entre lo objetivo y lo subjetivo, entre lo periodístico y lo literario, entre lo visto y lo sentido, entre lo real y lo imaginario, así como entre lo importante y lo intrascendente (Rotker, 1992, pp.106-14).

16 Mientras el término "anarquía" refiere a un estado, el término "anarquismo" señala un proceso ordenado y sistemático de aplicación de acontecimientos anárquicos. Para una discusión sobre esta distinción se puede consultar a Delgado (2017, pp. 19-24) y Colson (2003, pp. 30-31)
} 
Desde la perspectiva anárquica, el "misterioso no ser" al que todos los seres vivientes remiten en el fin de los tiempos parece expresar, justamente, la imposibilidad de adjudicar un origen o causa únicos a la existencia de cualquier entidad. La condición de no existencia asegura que esta entidad, por negada, pueda ser el origen de cualquier cosa desde que no existe como ninguna manifestación. Su "misterio" parece más un recurso expresivo de resonancias románticas para representar una existencia cuya enunciación paradójica afirma la imposibilidad siquiera de imaginarlo. Lo que importa aquí es que Barrett parece estar negando el origen único de todo ser al referirlo como el origen y el final simultáneos de todos los seres vivos, singulares o colectivos

La apelación al concepto anarquista del eterno retorno reafirma la existencia de los seres vivos en todos los momentos en tanto su constante y recurrente presencia permite exhibir toda su diversidad y según se manifiesten todas sus posibilidades. Asimismo, el eterno retorno no solo prioriza la idea de un tiempo cíclico-tal como se manifiestan los ciclos de la naturaleza-sino que establece también los ciclos de la vida y de la muerte sin atribuir ningún momento exclusivo de nacimiento (de un ser, de una especie) en la medida en que ese momento se comprende también como el momento de un fin.

En su negación del origen de cualquier especie como tal, el concepto del eterno retorno resuena con particular énfasis en los estudios ambientales, que han recurrido, en muchos casos, a las cosmogonías amerindias para habilitar ontologías que permitan a humanos y no humanos desarrollar vínculos sociales, de amistad, parentesco, compañía o supervivencia mutua. Eduardo Viveiros de Castro (2004) explica cómo la idea de una creación ex nihilo es inexistente en las cosmovisiones amerindias y cómo todos los seres vivos son el resultado no de una creación sino de una transformación, mientras que la cultura no es el resultado de una invención sino de una transferencia o transmisión (p. 477). En definitiva, se trata de una cosmogonía donde humanos y no humanos se transforman unos a partir de otros intercambiando posiciones ontológicas y estableciendo asociaciones que hacen de la naturaleza y la cultura categorías inexistentes.

La contradicción que merece ser atendida es aquella que, al tiempo que afirma la inexistencia de una separación entre naturaleza y cultura, aun como ideal, afirma la jerarquía de los seres humanos sobre el resto de los seres vivos. A partir de esta convicción, surgen algunas preguntas. ¿El ser humano puede ocupar un lugar privilegiado en un colectivo que se reconoce como tal? ¿Se trata de una contradicción? ¿Se puede hablar de colectivo en este caso? ¿La idea de una naturaleza a la que se accede al final, y como resultado, del proyecto moderno es elaborada también a partir de otras concepciones anárquicas?

La noción de anarquía, como estado de desorden en el sentido tradicional, no daría lugar a ninguna contradicción ya que, al interior de cualquier asociación o agrupación anárquica, los elementos se ubican en relaciones liberadas de cualquier vínculo establecido desde fuera. En todo caso, los diferentes puntos de vista son manifestaciones de fuerzas singulares que afectan inevitablemente otras fuerzas singulares (Colson, 2003, p. 83). La aceptación de fuerzas de distinto signo establece juegos de diferenciación y oposición tendientes a la construcción de un 
mundo liberado de toda dominación (p. 83). Sin embargo, junto a la noción de un mundo compartido por humanos y no humanos sin lugares jerárquicos aparece otra noción, de signo contrario, donde los seres humanos serían los portavoces de todos los seres vivos por lo cual, en el nombre de su liberación, se justificaría el proyecto moderno. En resumidas cuentas, ¿cómo el ser humano habría de liberar al resto de los seres vivos si aún no ha podido emanciparse de la explotación por sus semejantes?

En los términos del pensamiento de Nietzsche, la contradicción también desaparece como tal en la propia acción de un mismo individuo, de forma tal que el sujeto puede presentarse en cualquier ámbito y de la forma que considere necesaria de acuerdo con las circunstancias particulares de cada experiencia. Se trata de una forma de entender la acción donde el sujeto es capaz de adoptar todas las posiciones, cualesquiera sean, en su búsqueda de una autonomía completa. ${ }^{17}$

En cualquier caso, la multiplicidad de fuerzas que surgen al interior de una organización anárquica podrá alcanzar el equilibrio en la medida en que se comprenda también como una multiplicidad de puntos de vista (Colson, 2003, p. 83). Esta multiplicidad no opera como confusión sino, antes bien, como una virtud crítica y deseable en el fin de siglo. Su afirmación está en consonancia con lo que el anarquismo define como "individuación", es decir, aquel proceso donde el sujeto como tal se constituye como un devenir, como una emergencia o una resultante "a partir de un fondo ilimitado que aflora con todo su poder en cada uno de ellos, sin postas o fases intermediarias" (Colson, 2003, p.133). En este sentido, el sujeto anarquista se considera una entidad tanto individual como colectiva y se diferencia del sujeto tradicional en que se constituye a partir de metamorfosis constantes sin apelar a identidades específicas ni roles determinados. Por el contrario, el sujeto anarquista es un poseedor potencial de todo lo que puede ser, es decir, de "lo otro de ese orden" (p. 249, mi énfasis). De otra forma, un mismo individuo puede reunir, en este proceso, elementos diversos y disímiles de un contexto determinado para reproducirlos en una nueva entidad individual o colectiva, sea a través de su presentación pública, de una obra determinada, de un texto o de un volumen de

\footnotetext{
17 "No quedar pegado a una persona, ni siquiera a los más amados. Cada persona es una prisión, también un rincón. [. . ] No quedarse pegado al propio desapego, a esa voluptuosa lejanía y extrañeza del pájaro que huye cada vez más alto para ver cada vez más lo que hay debajo: el peligro del que vuela. No quedarnos pegados a nuestras propias virtudes y llegar a ser, en su conjunto, víctima de algún detalle en nosotros, tal como nuestra hospitalidad, que es el peligro de los peligros para las almas superiores y ricas que se gastan pródigamente, casi indiferentemente, y exageran la virtud de Generosidad en un vicio. Uno debe saber conservarse: la prueba más dura de la independencia" (Nietzsche, 1966, p. 52, mi traducción).
} 
textos. $^{18}$

Este proceso de individuación como devenir no sólo permite hacer convivir concepciones que se consideran tradicionalmente en oposición sino potenciarlas en virtud de su oposición y, por consiguiente, expresarlas exitosamente en virtud de esta potencia. Aún más, la idea de un sujeto como devenir o como resultado de una metamorfosis constante remite inevitablemente a las mencionadas cosmogonías amerindias, en el sentido de que el sujeto puede emerger, en el intercambio de perspectivas o puntos de vista, como aquello que se le opone ontológicamente en el sentido occidental y moderno, ya sea un predador, una presa, un ser humano muerto o un enemigo (Viveiros de Castro, 2004).

Como todo anarquista, Barrett no pudo estar alejado de las nociones ambientales de su época ni de la necesidad de apreciar las relaciones de asociación entre diferentes especies en términos evolutivos, como lo planteado por Piotr Kropotkin en su influyente Ayuda mutua (1902). Seguramente tuvo conocimiento de las nociones de evolución y revolución de Élisée Reclus, en particular de su concepción de una naturaleza degradada como parte del conflicto social (Reclus, 2004, pp. 123-124). Sin embargo, también estuvo inmerso en los sueños utópicos de la modernidad de su tiempo que ubicaron al ser humano como el redentor del mundo de acuerdo con nociones superhumanas, quizá, de base anarcoindividualista o nietzscheana. Esta aparente divergencia de intereses no obsta para que Barrett logre cristalizar, por medio de la individuación mencionada, el encuentro definitivo con la naturaleza que sobrevendría como la culminación del proyecto moderno. No es redundante insistir en la crónica cómo el género elegido por Barrett, en su capacidad para cultivar y explorar los distintos registros del conocimiento y de la experiencia, tal como se aprecia en el siguiente pasaje.

Los mitos artificiales y provisorios que se interponían entre la verdad y nuestro corazón, se han desvanecido. Nos hemos despedido de muchas fábulas delicadas, de muchas leyendas terribles; hemos renunciado a nuestro abolengo orgulloso y estéril. No somos ya hijos de los dioses. No está ya nuestra grandeza en el pasado, sino en el futuro. No es de arriba y de lejos de donde nos viene la vida, sino que nos envuelve, nos abraza, nos penetra. Semejantes a las plantas, sentimos las partes elevadas de nuestro ser besadas y agitadas por el viento libre, al tiempo que nuestras raíces, largas y tenaces, nos atan siempre mejor a las tinieblas fecundas. Y he aquí por qué amamos la tierra más sólidamente, más lúcidamente, más humanamente. (Barrett, s/f, p.86)

\footnotetext{
${ }^{18}$ Este proceso no es exclusivo del anarquismo ni del pensamiento de Nietzsche sino que es evidente y manifiesto, por ejemplo, en el eclecticismo artístico del período. La yuxtaposición de diferentes registros y géneros fue celebrada por el anarquismo rioplatense, como en el caso del dandy uruguayo Roberto de las Carreras o de los escritores argentinos Alberto Ghiraldo y Alejandro Sux (Delgado, 2015) así como cultivada por varios escritores cercanos al anarquismo, entre ellos Julio Herrera y Reissig (1978), quien definía al eclecticismo como "la quintaesencia del gusto" y "el punto más alto que debe alcanzar el crítico moderno", según expresaba en sus "Conceptos de crítica" (p. 279).
} 
No se trata solamente de observar una mera habilidad narrativa para reunir conceptos complejos y, en principio, disímiles. No es solamente una lucidez estética para cautivar públicos lectores. En los textos de Barret, la precisión científica es, más que indesmentible, avanzada para su época y su tarea como anarquista consistió, además, en hacer comprender estos conceptos a los grandes públicos que nacieron con el desarrollo urbano y el crecimiento de la prensa.

Esta capacidad del cronista para ampliar la comprensión de la noción Naturaleza/Cultura no solo tiene una correspondencia en los recientes estudios ambientales y su abordaje del problema ambiental desde la unión de las humanidades y las ciencias. El caso de Barrett constituye, también, uno de los ejemplos más completos de integración entre literatura y discurso científico. Si ocupa un lugar destacado en la tradición científico-literaria que comienza con la Ilustración hispanoamericana y llega hasta las observaciones naturalistas del siglo XIX, se puede afirmar que Barrett no ha tenido hasta el momento sucesores en este sentido.

\section{Conclusiones}

La existencia de elementos del pensamiento ambiental al interior del proyecto moderno permite pensar en otras perspectivas de observación del período que critiquen lo que se ve habitualmente como contradicciones características. El concepto anarquista de individuación logra proveer, en este caso, de una herramienta crítica, que podría permitir, además, trascender otras oposiciones centrales en la crítica del pensamiento ambiental. En este sentido, podría indagarse en otras expresiones de la modernidad que no fueron consideradas en el cánon modernista así como releer sus hitos.

Queda por analizar la obra de Barrett como la elaboración de una posible ecología política de comienzos del siglo XX. Esta discusión exige el diálogo con otros conceptos involucrados en la conformación de este campo de investigación y activismo. En tal discusión, sería oportuno vincular la noción de "lo colectivo" con otras análogas, tales como la de parentesco (kinship) de Donna Haraway (2016) o la de nuda vida de Giorgio Agamben (1998) que conducen, en última instancia, a pensar diferentes asociaciones entre humanos y no humanos. En este aspecto, estas nociones permitirían reflexionar e iluminar hacia una eventual trascendencia de las relaciones de explotación de unos humanos sobre otros.

Sobre el final, se puede hacer una observación sobre el corpus de este trabajo. Salvo El dolor paraguayo, cuya selección de crónicas fue realizada por el mismo Barrett, no sucede lo mismo con el resto de sus volúmenes, seleccionados y editados por primera vez en Montevideo en la primera década del siglo XX. Hasta el momento no existen ediciones que hayan respetado la producción y publicación cronológicas. Cabe preguntarse si su reflexión sobre la naturaleza resulta de considerar la totalidad de su obra como un proceso gradual de escritura. 


\section{Referencias}

Agamben, G. (1998). Homo Sacer. Sovereign Power and Bare Life. Stanford, California, USA: Stanford UP.

Agamben, G. (2004). The Open. Man and Animal. Stanford, California, USA: Stanford UP.

Albornoz, M. (2006-7). El instante de Rafael Barrett. Políticas de la memoria 6-7, pp.175-181.

Albornoz, M.(2007). Extranjería y anarquismo en Rafael Barrett. XI Jornadas Interescuelas / Departamentos de Historia. San Miguel de Tucumán: Departamento de Historia de la Universidad de Tucumán, San Miguel de Tucumán. Recuperado de: https://cdsa.aacademica.org/000-108/321.pdf [Accedido en diciembre de 2020]

Alcina Franch, J. (Comp.) (1990). Indianismo e indigenismo en América. Madrid, España: Alianza.

Ansolabehere, P. (2011). Literatura y anarquismo en Argentina (1879-1919). Buenos Aires, Argentina: Beatriz Viterbo.

Barrett, R. (s/f). Ideas y críticas. Montevideo, Uruguay: Osiris Bertani.

Barrett, R. (1910). Lo que son los yerbales. Montevideo, Uruguay: Osiris Bertani.

Barrett, R. (1911). El dolor paraguayo. Montevideo, Uruguay: Osiris Bertani.

Barrett, R. (1912a). Al margen. Montevideo, Uruguay: Osiris Bertani.

Barrett, R. (1912b). Mirando vivir. Montevideo, Uruguay: Osiris Bertani.

Barrett, R. (2012). Crónicas de la naturaleza. Montevideo, Uruguay: Biblioteca Artigas.

Berman, M. (1988). All That Is Solid Melts Into Air. The Experience of Modernity. New York, USA: Penguin.

Bollo, S. (1976). El modernismo en el Uruguay. Montevideo, Uruguay: División Publicaciones y Ediciones de la Universidad de la Universidad de la República.

Carroll, J. (2003) Break-Out from the Crystal Palace: The Anarcho-Psychological Critique: Stirner, Nietzsche, Dostoevsky. Londres y Boston: Routledge.

Colson, D. (2003). Pequeño léxico filosófico del anarquismo. De Proudhon a Deleuze. Buenos Aires, Argentina: Nueva Visión. 
Corral, F. (1994). El pensamiento cautivo de Rafael Barrett. Crisis de fin de siglo, juventud del 98 y anarquismo. Madrid, España: Siglo XXI.

Cronon, W. (1994) The Wealth of Nature: Environmental History and the Ecological Imagination. New York, USA: Oxford UP.

Cronon, W. (1995). The Trouble with Wilderness; or, Getting Back to the Wring Nature. En W. Cronon (Ed.), Uncommon Ground: Rethinking the Human Place in Nature (pp.69-90). New York, USA: W.W. Norton \& Company.

Delgado, L. (2010). La participación del anarquismo en la formación del intelectual autónomo en el Río de la Plata (1900-1930). A Contracorriente: Revista de Historia Social y Literatura en América Latina, 8(1), pp. 163-97.

Delgado, L. (2012). Prólogo. En R. Barrett Crónicas de la Naturaleza. Montevideo: Clásicos Uruguayos, pp. 7-36.

Delgado, L. (2015). Escrituras anárquicas: prácticas textuales del anarquismo en el Rio de la Plata. Culturales, 22(2), 2015, pp. 45-74.

Delgado, L. (2017). Anarquismo en el Novecientos rioplatense: cultura, literatura y escritura. Montevideo, Uruguay: 2017.

Gudynas (1999). Concepciones de la naturaleza y desarrollo en América Latina. Persona y Sociedad, 13(1), pp.101-125.

Gullol, R. (1974a). Exotismo y modernismo. En H. Castillo (Ed.) Estudios críticos sobre el modernismo (pp. 267-278). Madrid, España: Gredos.

Gullol, R. (1974b) Indigenismo y modernismo. En H. Castillo (dE.) Estudios críticos sobre el modernismo. Madrid: Gredos, pp. 279-298.

Habermas, J. (s/f). Modernity. An incomplete Project. Recuperado de: https://www.academia.edu/14879176/Jurgens_Habermas_Modernity_an_i ncomplete_project [Accedido en julio de 2020].

Haraway, D. (1991). Simians, Cyborgs and Women: The Reinvention of Nature. New York, USA: Routledge.

Haraway, D. (2003). The Companion Species Manifesto: Dogs, People, and Significant Otherness. Chicago, USA: Prickly Paradigm Press.

Haraway, D. (2016). Staying with the Trouble. Making Kin in the Chthulucene. Durhams y Londres: Duke UP.

Harvey, D. (2004) La condición de la posmodernidad. Investigación sobre los orígenes 
del cambio cultural. Buenos Aires, Argentina: Amorrortu.

Herrera y Reissig, J. (1978). Poesía completa y prosa selecta. Caracas, Venezuela: Ayacucho.

Hierro Gambardella L. (1967). Prólogo. En R. Barrett Cartas íntimas. Montevideo, Uruguay: Clásicos Uruguayos.

Karlsson, B.G. (2015). Political Ecology: Anthropological Perspectives. En J.D. Wright (Ed.), International Encyclopedia of the Social \& Behavioral Sciences. Segunda edición, 18, (pp. 350-355) Oxford, UK: Elsevier.

Koch, A.M. (2004). Dionysian Politics: The Anarchistic Implications of Friedrich Nietzsche's Critique of Western Epistemology. En J. Moore (Ed.), I Am Not a Man, I Am Dynamite: Friedrich Nietzche and the Anarchist Tradition (pp. 49-63). NewYork, USA: Autonomedia.

Kropotkin, P. Mutual Aid: A Factor of Evolution (1902). Anarchy Archives: An Online Research Center on the History and Theory of Anarchism. Recuperado de: http://dwardmarc.pitzer.edu/Anarchist_Archives/kropotkin/mutaidconten ts.html. [Accedido en julio de 2020].

Latour, B. (2004). Politics of Nature. How to Bring the Sciences into Democracy. Londres, UK: Harvard UP.

Latour, B. (2007). Nunca fuimos modernos. Ensayo de antropología simétrica. Buenos Aires, Argentina: Siglo XXI.

Latour, B. (2017). Cara a cara con el planeta. Una nueva mirada sobre el cambio climático alejado de las posiciones apocalípticas. Buenos Aires, Argentina: Siglo XXI.

Latour, B. (2018). Down to Earth. Politics in the New Climate Regime. Cambridge, UK: Polity.

Martínez, V. (2017). La vida es tempestad. Historia de la familia Barrett. Literatura, resistencia y revolución. Montevideo, Uruguay: Ediciones de la Banda Oriental.

Merleau-Ponty, M. (1993). Fenomenología de la percepción. Barcelona, España: Planeta.

Moore, J. (1997). Public Secret. Fredy Perlman and the Literature of Subversion. En J. Purkis Jon y J. Bowen (Eds.) Twenty First Century Anarchism: Unorthodox Ideas For a New Millenium, (pp.117-130). Londres, UK: Cassell.

Moore, J. (2004). Attent Art: Anarchism and Nietzsche's Aesthetics. En J. Moore (Ed.) I Am Not a Man, I Am Dynamite: Friedrich Nietzche and the Anarchist 
Tradition, (pp.127-142). NewYork, USA: Autonomedia..

Morán G. (2007). Asombro y búsqueda de Rafael Barrett. Barcelona, España: Anagrama.

Morton, T. (2016). Dark Ecology: For a Logic of Future Coexistence. New York, USA: Columbia UP.

Morton, T. (2017). Humankind: Solidarity with Non-Human People. Londres, UK: Verso.

Muñoz, V. (1977). El pensamiento vivo de Rafael Barrett. Buenos Aires, Argentina: Rescate.

Nietzsche, F. (1966) Beyond Good and Evil. New York, USA: Vintage.

Paz, O. (1990). Los hijos del limo. Del romanticismo a la vanguardia. Barcelona, España: Seix Barral.

Reclus. E. (2004). The Feeling of Nature in Modern Society [1866]. En J.P. Clark y Camille Martin (Eds.) Anarchy, Geography, Modernity. The Radical Social Thoughts of Elisée Reclus, (pp.119-127). Oxford, UK: Lexington.

Roa Bastos, A. (1978). Rafael Barrett: descubridor de la realidad social del Paraguay. En R. Barrett El dolor paraguayo. Caracas, Venezuela: Ayacucho.

Rotker, S. (1992). La invención de la crónica. Buenos Aires, Argentina: Letra Buena.

Viveiros de Castro, E. (2004). Exchanging Perspectives. The Transformation of Objects into Subjects in Amerindian Ontologies. En J.M. Perl. Talking Peace with Gods: Symposium on the Conciliation of Worldviews: Part 1. Common Knowledge 10(3), pp.463-484.

Wasem, M. (2015). El amor libre en Montevideo. Roberto de las Carreras y la irrupción del anarquismo erótico en el Novecientos. Montevideo, Uruguay: Biblioteca Nacional y Ediciones de la Banda Oriental.

Worster, D. (1995). Nature and the Disorder of History. En M. Soulé y E.Y. Gary (Eds.). Reinventing Nature? Responses to Posmodern Deconstruction, (pp.65-85) Washington DC, USA: Alhambra.

Worster, D. (1996). The Two Cultures Revisited: Environmental History and the Environmental Sciences. Environment and History, 2, pp.3-14. 